\title{
REVIEW
}

\section{The hepatocyte growth factor system as a regulator of female and male gonadal function}

\author{
Rob Zachow and Mehmet Uzumcu' \\ Department of Physiology and Biophysics, Robert Wood Johnson Medical School-UMDNJ, 675 Hoes Lane West, Piscataway, New Jersey 08854, USA \\ ${ }^{1}$ Department of Animal Sciences, School of Environmental and Biological Sciences, Rutgers, The State University of New Jersey, 84 Lipman Drive, \\ New Brunswick, New Jersey 08901-8525, USA \\ (Correspondence should be addressed to R Zachow; Email: zachowrj@umdnj.edu)
}

\begin{abstract}
The hepatocyte growth factor (HGF) system comprises HGF, its receptor (the c-met tyrosine kinase), HGF activator (HGFA) protein, and HGFA inhibitor (HAI). The components of the HGF system have been identified in a plethora of tissues to include the ovary and testis. In its traditional context, the HGF system works via paracrine- and autocrine-mediated feedback in which HGF (of mesenchymal origin) binds and activates c-met (within epithelial cells); target cells then respond to HGF via any number of morphogenic and functional changes. The concomitant presence of HGFA and HAI suggests that HGF bioactivity can be locally modulated. A number of studies have collectively shown that the mammalian ovary and testis contain HGF, c-met, and HGFA; very little is currently known regarding HAI within the gonad. Within the ovary, HGF controls numerous key functions which collectively regulate the growth and differentiation of ovarian follicles; these include
\end{abstract}

cell growth, steroidogenesis, and apoptosis within theca cells and/or granulosa cells. Comparatively, less is known about the function of HGF within the testicular Leydig and Sertoli cells, but evidence is emerging that HGF may regulate somatic cell function, including Leydig cell steroidogenesis. Changes in the cellular origin of HGF and c-met during fetal and postnatal testicular development suggest that HGF, in collaboration with other growth factors, may regulate important aspects of testicular cell morphogenesis and differentiation which enable male sexual viability. Likewise, experimental evidence showing that HGF can modulate many vital processes which enable ovarian follicle growth, differentiation, and function indicate the importance of HGF in female reproduction. This review presents what is currently known regarding the expression of the HGF system and its function within the ovary and testis.

Journal of Endocrinology (2007) 195, 359-371

\section{The hepatocyte growth factor (HGF) system}

HGF is an $87 \mathrm{kDa}$ growth factor first identified and characterized due to its angiogenic and proliferative effects in primary epithelial cell cultures (Bussolino et al. 1992). This pioneered a number of studies leading to the localization of HGF within mesenchymal cell populations. As such, one key function of HGF is its action as a paracrine factor. In this context, HGF is secreted from mesenchymal cells and targets neighboring epithelial cells which express the HGF receptor, c-met (Gheradi \& Stoker 1991). Thus, at the tissue level, the $\mathrm{HGF} / \mathrm{c}$-met system represents a paracrine control mechanism for the local regulation of tissue function.

HGF is synthesized as an inactive $97 \mathrm{kDa}$ single chain precursor, and is processed to yield its bioactive disulfide-linked heterodimer (Miyazawa et al. 1989, Nakamura et al. 1989). Another component of the HGF system is HGF activator (HGFA) protein. This molecule is a serine protease which cleaves the immature HGF precursor molecule to form mature bioactive
HGF (Miyazawa et al. 1993). Thus, the concomitant presence of both HGF and HGFA within a tissue microenvironment is presumed to exert some level of control upon HGF bioactivity. Relatively little is known about the regulation of HGFA expression; however, the presence of HGFA has been established within the rat ovary (discussed below; Uzumcu et al. 2006).

The most recent addition of the HGF system to be identified is HGFA inhibitor protein (HAI; Shimomura et al. 1997). This protein is a Kunitz-type serine protease inhibitor, which, as the name implies, blocks the activation of HGFA. One study to date has demonstrated the presence of the mRNAs encoding HAI-1 and HAI-2 within the human testis (Yamauchi et al. 2002). The function of HAI has not been reported within the testis, and neither the expression nor functions of HAI have been described within the ovary.

The HGF receptor, identified as the p190 c-met protooncogene, is a member of the receptor tyrosine kinase family (Bottaro et al. 1991). In its mature bioactive form, plasma 
membrane-bound c-met comprises disulfide-linked $\alpha$ and $\beta$ chains; with a protein tyrosine kinase (PTK) domain (residues Y1349 and Y1356) nested within carboxyl terminus of the $\beta$ chain (Gonzatti-Haces et al. 1988, Giordano et al. 1989, Peruzzi $\&$ Bottaro 2006). Upon activation by HGF, c-met PTK activity is coupled to the recruitment of several adaptor proteins including the non-receptor PTK Src, the adaptor protein SHC, growth factor receptor-bound protein 2 (Grb2), and Grb-2-associated binder (Gab1) (Peruzzi \& Bottaro 2006), followed by mobilization of numerous signaling cascades. Examples of HGF-induced signaling motifs include those mediated by cyclic nucleotides, phosphosinositide-3 kinase (PI-3K)/protein kinase $\mathrm{B}$ (Akt), mitogen-activated protein kinases, calcium-phospholipids/protein kinase $\mathrm{C}$, and Janus kinase/signal transducer and activator of transcription (Baffy et al. 1992, Lail-Trecker et al. 1998, Liu 1999, Zachow \& Woolery 2002, Makondo et al. 2004). Pathways coupled to the regulation of cell cycle progression, morphogenesis, and cell survival are among those under the control of HGF/c-met-dependent signaling (Peruzzi \& Bottaro 2006).

\section{Ovarian function}

\section{Folliculogenesis}

Folliculogenesis is a dynamic process during which follicular granulosa cells (GCs) and theca cells proliferate and differentiate to produce factors (e.g., steroid and peptide hormones and growth factors) which, through autocrine, paracrine, and endocrine pathways, support oocyte maturation and enable ovulation. In a general sense, folliculogenesis is dependent upon the pituitary gonadotropins: follicle-stimulating hormone (FSH) and luteinizing hormone (LH). Within preovulatory follicles, LH stimulates the production and secretion of the aromatizable androgens (androstenedione and testosterone) in theca cells. Whereas FSH targets GC, and upregulates the expression and activity of cytochrome P450 aromatase (CYP19) enabling the aromatization of theca cell androgens into estradiol-17 $\beta\left(E_{2}\right)$. Ovarian androgens and $E_{2}$ are necessary for normal reproductive function; importantly, aberrant levels of ovarian steroids have been coupled to infertility and certain reproductive pathologies such as polycystic ovary syndrome (Erickson 1994, Ehrmann 2005). Hence, tight regulation of the production of androgens and $E_{2}$ is important for controlling both normal and pathologic intra- and extraovarian processes.

Decades of research have shown that several intraovarian growth factors work with the gonadotropins and facilitate folliculogenesis through an array of autocrine and paracrine mechanisms which control follicle growth and steroidogenesis (Webb et al. 2004, Barnett et al. 2006, Knight \& Glister 2006). It is important to realize that a number of growth factors have been localized within growing follicles, and many of these work through the activation of receptor PTK, with HGF being one such factor. Some other examples of these which have been shown to regulate important aspects of follicle cell function are insulin and insulin-like growth factor-I (IGF-I), epidermal growth factor, transforming growth factor- $\alpha$ (TGF- $\alpha$ ), vascular endothelial growth factor (VEGF), basic fibroblast growth factor (FGF), neurotrophins, and kit ligand (reviewed in Fortune 2003, Skinner 2005). Interestingly, these receptor PTKs often induce signaling mechanisms common to one another and result in overlapping cell responses. Of course, there are many other growth factors and cytokines (e.g., TGF- $\beta$ and its family members, tumor necrosis factor- $\alpha$, interleukins, and others) using non-PTK mechanisms of action; each of which also mobilize some similar signaling cascades (Magoffin 1991, Terranova 1991). Such observations support the belief that an intricate web of cooperation occurs between the gonadotropins and the numerous growth factor/cytokine-dependent control mechanisms which mediate follicle cell differentiation and function. In this review, we suggest that the mesenchymalepithelial paracrine mechanism, an example of which is mediated by HGF, is one example of the many important components which guide follicle development and ovulation.

Interestingly, of the vast number of follicles that are recruited from the non-growing ovarian follicular reserve to develop during each reproductive cycle (e.g., the menstrual cycle in primates and the estrus cycle in rodents), few (arguably $<1 \%$ ) of these follicles will ever fully mature and ovulate. Instead, all but the so-called selected follicles (i.e., those follicles which will ovulate) die by the process known as atresia. Apoptosis, especially within GC, has been shown to be a predominant cellular mechanism that leads to follicular atresia (Hussein 2005). Based upon a plethora of in vivo and in vitro studies using animal models, FSH is required to maintain follicle (e.g., GC) viability.

It is important to consider that, although FSH is a key folliculogenic hormone, the modulation of FSH bioactivity by intraovarian growth factors also regulates steroidogenesis, and can prevent or promote apoptosis in GC (Hsueh et al. 1996, Kaipia \& Hsueh 1997). It seems that gonadotropin action in the ovary is primarily mediated by local growth factors (Hillier 2001, Conti et al. 2006). Using transgenic mice to create selective gene knockouts, it has also been shown that certain intraovarian growth factors are in fact vital for the process of folliculogenesis (Burns \& Matzuk 2002, Roy \& Matzuk 2006).

\section{The HGF system and folliculogenesis}

During the female reproductive lifespan, follicles are recruited from a latent resting pool of primordial follicles into a growing cohort (often referred to as the primordial to primary follicle transition). Throughout the growth phase, follicles pass through several stages of growth and differentiation which involves the exquisite temporal regulation of cell proliferation, morphogenic and functional differentiation, angiogenesis, apoptosis, and motogenesis. Ovulation of the selected follicle results in its rupture with concomitant damage to the ovarian surface epithelium; this is followed by epithelial repair and terminal differentiation of the remnant ovulated follicle into the corpus luteum. As such, the complete course of folliculogenesis (including ovulation and luteogenesis) represents a unique 
example of ongoing tissue growth with angiogenesis, insult, repair, and degeneration in adult mammals. When considering this, a remarkable comparison can be made between this vital and healthy event and oncogenesis, the latter involving one or more of the aforementioned processes escaping from normal control. Many studies have documented that mutations in HGF, c-met, or overexpression of HGF and/or c-met occur in numerous cancers (e.g., breast, prostate, ovarian surface epithelial, non-small cell lung, and others; Maulik et al. 2002); moreover, HGF has been shown to regulate many processes involved in tumorigenesis (e.g., cell cycle control, invasion, motility, apoptosis, angiogenesis, and branching morphogenesis; Maulik et al. 2002). Although a description of the involvement of the $\mathrm{HGF} / \mathrm{c}-\mathrm{met}$ system in oncogenesis is beyond the scope of this review, the fact that HGF can mediate many of these mechanisms in (healthy) growing follicles, as well as tumor cells, is compelling. Future studies which reveal how the normal and pathologic processes which are regulated by HGF compare at the molecular level are likely to be beneficial for furthering our understanding of how timed cycles of growth, differentiation, injury, and repair switch from normal to an oncogenic course. The remaining discussion of ovarian function describes what is currently known about the role of the HGF/c-met system during normal follicle development.

Both HGF and c-met are expressed within mammalian ovaries as has been shown in the human, rat, pig, cow, and mouse (Liu et al. 1994, Parrott et al. 1994, Parrott \& Skinner 1998a, Osuga et al. 1999, Shimizu et al. 2003). Importantly, intraovarian HGF is an autocrine/paracrine regulator of GC and theca cell growth and steroidogenesis (Zachow et al. 1997, 2000, Lail-Trecker et al. 1998, Parrott \& Skinner 1998b, Zachow \& Woolery 2002).

The cellular localization of HGF within the mammalian ovary was first demonstrated by Parrott et al. (1994). This study showed that HGF mRNA and protein were present within bovine theca cells; whereas, HGF was not detected within bovine GC. Moreover, in bovine GC in vitro, HGF induced cell proliferation, but did not induce theca cell growth (Parrott et al. 1994). This established the basic mesenchymal-epithelial cell model for HGF bioactivity (described above) within the mammalian ovary. Subsequent studies demonstrated that in addition to theca cells, HGF 1) is expressed within GC and 2) can modulate both theca cell and GC function, as described below.

\section{Theca cells}

The steroid modulatory effects of HGF were first demonstrated using primary cultures of theca-interstitial cells from sexually immature rats. In rat theca cells in vitro, HGF suppressed LH-dependent androsterone secretion, while also blocking the steady-state level of CYP17 expression (Zachow et al. 1997). Basal and LH-induced progesterone production were stimulated in the presence of HGF; but neither the expression of CYP11A nor $3 \beta$-hydroxysteroid dehydrogenase was affected by HGF
(Zachow et al. 1997). Although steroidogenesis was modulated by HGF, DNA content in rat theca cell cultures was not altered, suggesting that HGF did not stimulate proliferation of these cells. Using quantitative RT-PCR, this same study also demonstrated that, in the immature rat, HGF mRNA was expressed in both theca cells and GCs (Zachow et al. 1997). Therefore, in contrast to what was observed in the cow (Parrott et al. 1994), in the immature rat, HGF is expressed within both follicle cell populations.

The direct effect of HGF on theca cell function was questioned early on, in fact it was postulated that the HGF-correlated regulation of theca cell steroidogenesis was indirect; that is, due to actions of HGF in contaminating GC within theca cell cultures, which secreted steroid regulatory factors (Lail-Trecker et al. 1998). More recent data support the initial model reported by Zachow et al. (1997) suggesting a direct effect of HGF on theca cell function. Specifically, as shown by Uzumcu et al. (2006) the in vivo priming of immature rats with equine chorionic gonadotropin (eCG; to induce the growth of mature preovulatory follicles) resulted in elevated HGF and c-met immunoreactive proteins within the theca cells of large antral follicles. Also, c-met expression has been detected in human theca cells (Ito et al. 2001). Furthermore, in human chorionic gonadotropin (hCG)primed gilts, c-met mRNA is expressed within theca cells (Shimizu et al. 2003). Thus, experimental evidence shows that both HGF and c-met are produced by theca cells as well as GC. Moreover, theca cells are likely respond to direct stimulation by HGF with changes in steroidogenic gene expression leading to alterations in androgen and progesterone production (Zachow et al. 1997).

The effects of HGF within theca cells are not restricted to the modulation of steroidogenesis. As shown by Parrot et al. in bovine theca cells in vitro, hCG stimulated the production of HGF (Parrott \& Skinner 1998b). This initiated a paracrine feedback loop whereby theca-derived HGF promoted the secretion of kit ligand from GC. Kit ligand in turn 1) upregulated the production of HGF within theca cells and 2) induced theca cell proliferation (Parrott \& Skinner 1998b, 2000). An essentially identical HGF-kit ligand system was also demonstrated in human theca cells and GC in vitro (Ito et al. 2001).

The presence of ovarian HGFA has been reported (Uzumcu et al. 2006); recall that HGFA represents a potential control mechanism for regulating local bioactive HGF concentrations. As first published by Uzumcu et al. (2006), in non-primed rat ovaries, a somewhat uniform HGFA signal was observed in GC within, and theca cells surrounding, preantral follicles; however, immunoreactive HGFA was not detected in oocytes. The same general pattern of HGFA was apparent within the antral follicles contained within these ovaries. In the ovaries of eCG-primed immature rats, a more intense signal for HGFA was present in theca cells when compared with that detected within GC. This pattern for HGFA was especially apparent in the theca cells associated with large antral follicles. The GC within large antral follicles showed no immunoreactive HGFA (Uzumcu et al. 2006). 


\section{Granulosa cells}

Expression of the HGF system The proliferation and steroidogenic differentiation of GC into estrogenic and ultimately progestagenic cells is vital for reproductive function. Since the control of GC differentiation into steroidogenic cells is critical for maintaining female reproductive viability, any factor which modulates GC function is of potential importance in this context. The first studies showing an effect of HGF within the ovary were conducted by Parrott et al. (1994) in which HGF induced proliferation of bovine GC in vitro. This indicated that GC contain functional c-met, and this was indeed established shortly thereafter when the expression of c-met mRNA was identified in mouse GC (Yang \& Park 1995). Subsequently, it was demonstrated that FSH and HGF each reduced c-met expression in rat GC in vitro (Zachow et al. 2000). Whereas, the cAMP analog, dibutyrylcAMP, increased the level of c-met mRNA in cultured rat GC (Zachow et al. 2000). This was a compelling set of observations since FSH stimulates a profound increase in cAMP production in GC; hence, at a first approximation, these data showing changes in the level of c-met expression appeared paradoxical. One explanation for these observations is that FSH mobilizes a variety of signaling molecules, and crosstalk between cAMPmediated and non-cAMP-mediated signaling cascades could control c-met content in GC.

Further studies investigating the regulation of ovarian c-met content were conducted by Uzumcu et al. (2006). As reported by these authors using ovaries harvested from immature rats, immunoreactive c-met staining was the most intense in GC within small preantral follicles; however, following eCG priming of immature rats (to induce the growth of large antral follicles), there was a shift in c-met intensity which resulted in relatively low c-met levels in GC, but relatively high $\mathrm{c}$-met content in theca cells surrounding large antral follicles (Uzumcu et al. 2006).

The early report by Parrott et al. (1994) by-and-large strengthened the belief that HGF worked via the basic mesenchymal-epithelial mechanism of action that was proposed following its identification in epithelial cell cultures (Bussolino et al. 1992). However, subsequent studies challenged this model by showing that human, rat, and pig GC not only express c-met, but also contain HGF (Zachow et al. 1997, Osuga et al. 1999, Shimizu et al. 2003, Uzumcu et al. 2006). In the rat, eCG priming induced a reduction in immunoreactive HGF in GC, while increasing the HGF signal in theca cells of large antral follicles (Uzumcu et al. 2006). It is therefore important to consider that HGF is not expressed in theca cells and GC alone, but the level of ovarian HGF is subject to hormonal regulation in vivo (Uzumcu et al. 2006).

HGF and GC steroidogenesis Since a HGF system has been localized within the ovary, it is not surprising that HGF affects several key aspects of GC function as has been shown by numerous in vitro studies. In GC obtained from human in vitro fertilization (IVF) patients, HGF stimulated progesterone production (Ito et al. 2001). In contrast, in the rat HGF did not alter FSH-stimulated progesterone production, nor that induced by combined treatment with FSH and IGF-I in GC cultures (Zachow \& Woolery 2002). Whereas in bovine GC, HGF suppressed hCG-supported progesterone synthesis (Parrott \& Skinner 1998a). Therefore, depending upon the species, and perhaps the state of follicle differentiation, HGF can cause changes in progesterone production, and may thus exert control over luteogenesis and/or corpus luteum function.

One hallmark feature of folliculogenesis is the steroidogenic differentiation of theca cells and GC which appears to occur sometime during late the preantral or early antral phases of follicle growth. Within GC, theca cell androgens are aromatized into estrone $\left(E_{1}\right)$, which is subsequently converted into $E_{2}$ by $17 \beta$-HSD type 1 . Through this cooperation, the GCs within preovulatory follicles account for the majority of the preovulatory rise in serum $E_{2}$; and these changes in serum $E_{2}$ lead to the pattern of gonadotropin secretion which enables ovulation. Although the steroidogenic differentiation process is held in check in small preantral follicles in vivo, GC harvested from preantral follicles will produce copious amounts of $E_{2}$ when challenged with FSH or cAMP analogs (in the presence of aromatizable androgens) in vitro (Erickson 1983). Likewise, theca cells obtained from sexually immature rat ovaries will secrete substantial quantities of androgen in the presence of LH in vitro (Erickson 1983). Thus, it appears that the GC and theca cells in immature follicles, which do not produce appreciable amounts of androgens and $\mathrm{E}_{2}$ in vivo, have an abundant steroidogenic capacity when removed from the in vivo milieu. These observations have led to the development of a model suggesting that one or more factors within the follicular microenvironment most likely restrain $\mathrm{E}_{2}$ production in less immature (preantral) GC by directly impairing CYP19 and/or blocking the production of theca cell androgens. Although some of these factors, such as growth differentiation factor- 9 and bone morphogenetic protein-15 are produced and secreted by oocytes (Vitt et al. 2000, Matzuk et al. 2002, McNatty et al. 2005), somatic cell-derived factors, including HGF, regulate follicular cell proliferation, differentiation, and steroidogenesis. This notion is supported by the fact that many intraovarian growth factors have been identified, including HGF, which modulate both FSH-directed $\mathrm{E}_{2}$ synthesis in GC and LH-supported androgen production in theca cells (Magoffin 1991, Terranova 1991).

As shown by Zachow et al. in immature rat GC in vitro, HGF blocked $\mathrm{E}_{2}$ production that was stimulated by $\mathrm{FSH}$ and $\mathrm{FSH}$ in the presence of IGF-I (Zachow \& Woolery 2002). Interestingly, while $\mathrm{HGF}$ did not suppress $\mathrm{FSH}$-stimulated $\mathrm{E}_{1}$ production in rat GC, HGF did block the aromatization of androstenedione into $\mathrm{E}_{1}$ which is promoted by FSH and IGF-I (Zachow \& Woolery 2002). These effects were correlated to changes in CYP19 expression and activity, as well as modulation of the level of $17 \beta-H S D$ type 1 mRNA; indicating that, dependent upon the hormonal milieu, HGF can block the metabolism of androstenedione at one or more loci within the estrogenic pathway (Parrott \& Skinner 1998a, Zachow et al. 2000). 
A recent and interesting observation supported the above evidence that $H G F$ suppresses $E_{2}$ production in immature follicles. In GC harvested from human follicles from non-IVF patients, HGF impaired $\mathrm{E}_{2}$ production in $\mathrm{GC}$ isolated from small diameter preantral follicles. Whereas, HGF did not significantly impair $\mathrm{FSH}$-dependent $\mathrm{E}_{2}$ production in $\mathrm{GC}$ harvested from the larger, antral human follicles (Zachow unpublished observations; Fig. 1). This indicates that the suppressive effects of HGF are sensitive to the state of GC maturation since different effects were detected in GC from small versus large diameter follicles. In addition, in the GC that were harvested from younger follicles, HGF did not impair $E_{2}$ production in the presence of the highest dose of FSH tested (Fig. 1). One interpretation of these observations is that HGF dampens $\mathrm{E}_{2}$ synthesis in immature GC (i.e., those harvested from immature follicles); however, as GC mature (i.e., those harvested from large diameter follicles), and as $\mathrm{FSH}$ concentrations rise, yet-to-be defined mechanisms impair the ability of HGF to attenuate FSH-directed $\mathrm{E}_{2}$ production in GC. One plausible candidate for this downregulatory effect is at level of c-met content in GC, since FSH, HGF, and eCG each down-modulated c-met mRNA or protein in vivo and in GC cultures as described above (Zachow et al. 2000, Uzumcu et al. 2006). These observations further support the hypothesis that a developmental switch, perhaps at the level of c-met expression, occurs in GC which overcomes or prevents the suppressive effect of $\mathrm{HGF}$ on $\mathrm{E}_{2}$ secretion. This concept also fits within the physiologic context of what occurs during folliculogenesis in vivo (i.e., a switch from non-estrogenic to estrogenic GC); and the identification of HGF as a modulator of this intricate and tightly regulated process is compelling.
HGF signaling mechanisms in GC Relatively few studies have attempted to reveal the intracellular mechanisms of action used by HGF in GC. As reported by Zachow \& Woolery (2002), the HGF-induced block in FSH-supported $\mathrm{E}_{2}$ synthesis was prevented by dibutyryl-cAMP or the cAMP phosphodiesterase inhibitor, isobutylmethylxanthine. Thus, it appeared that HGF down-modulated the FSH-directed cAMP signaling cascade upstream from cAMP production or by promoting the degradation of cAMP. Further investigations revealed that in rat GC, cAMP production was indeed impaired by HGF; whereas, cGMP production was elevated by HGF. The latter effect is interesting since the induction of cGMP signaling impairs FSH-stimulated $\mathrm{E}_{2}$ production in rat GC (LaPolt \& Hong 1995); although a direct link between HGF-induced cGMP production and its inhibitory effect of $\mathrm{E}_{2}$ synthesis has not been reported. In addition, the activities of FSH-dependent cAMP and cGMP phosphodiesterases were each reduced by HGF in a time-dependent manner (Zachow \& Woolery 2002). The best interpretation of these data is that a complex array of effects leading to cyclic nucleotide production and degradation in GC are modulated by HGF; however, further research is required to couple these mechanisms with the observed HGF-stimulated changes in steroidogenesis.

In addition to its modulatory actions on $E_{2}$ and progesterone production, HGF blocks apoptosis in cultured rat follicles and isolated immature rat GC (Uzumcu et al. 2006). Although not linked within the same study, it was discovered that HGF caused biphasic increases in the steady-state level of Akt1 mRNA, and as described above, HGF increased cGMP content in GC (Zachow et al. 2000,

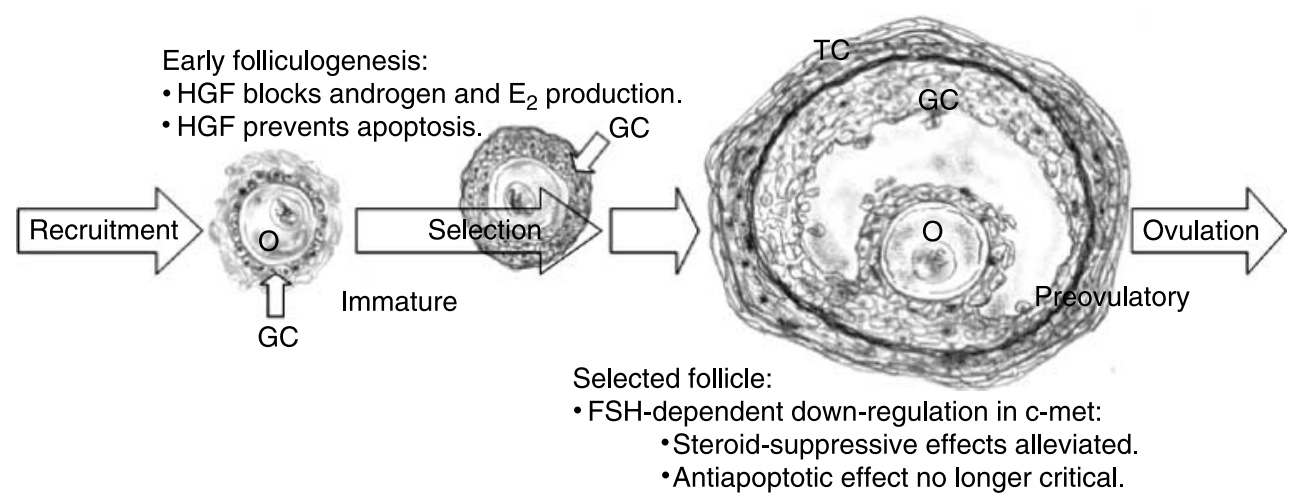

Figure 1 A model for HGF in promoting folliculogenesis. Upon recruitment into a growing cohort, follicles undergo an orderly course of morphogenesis that involves cell proliferation and functional differentiation into a steroidogenic tissue. Follicles destined for ovulation are selected from the growing cohorts; whereas, apoptosis within non-selected follicles leads to atresia. Data show that HGF blocks gonadotropin-stimulated androgen and $\mathrm{E}_{2}$ production in TC and GC respectively. When combined with the anti-apoptotic effects of $\mathrm{HGF}$ that have been shown in immature rat GC, this concomitant mechanism would support the viability of younger follicles; it is proposed that this control system is functional in follicles destined for selection. FSH has been shown to reduce cmet expression in GC, and eCG lowers C-met content in the GC within large antral follicles in vivo as described in this review. It follows that a downregulation in c-met content would diminish HGF bioactivity in the dominant follicle; thereby releasing the production of androgens, CYP19 activity, and the secretion of $\mathrm{E}_{2}$ which is a vital feedback vehicle for triggering ovulation. TC, theca cells, GC, granulosa cells; and O, oocyte. 
Zachow \& Woolery 2002). This is potentially significant in that the activation of PI-3K/Akt- and cGMP-dependent signaling mechanisms block apoptosis in GC (Westfall et al. 2001, Peluso \& Pappalardo 2004). Collectively, these findings imply that the anti-apoptotic effect of HGF within GC may be mediated by the induction of PI-3K/Akt and/or cGMPdependent signal transduction. A review of some signaling mechanisms that are used by HGF is presented in Fig. 2.

With these data assembled, it is apparent that HGF can control every major component of folliculogenesis: 1) theca cell and GC steroidogenesis, 2) theca cell and GC growth and differentiation, and 3) GC apoptosis (reviewed in Table 1). Collectively, these effects strengthen the credibility for an in vivo function of HGF in supporting the progression of folliculogenesis from preantral growth to selection of the dominant follicle(s) and ovulation. One attractive model that is supported by the available data centers around shifting levels of c-met and HGF between theca cells and GC as folliculogenesis proceeds. As shown in Fig. 3, during early follicle development, the steroid modulatory effects of HGF would keep the intraovarian concentrations of androgens and $\mathrm{E}_{2}$ at bay. In more mature antral follicles, a gonadotropindirected reduction in c-met content in GC would alleviate the anti-estrogenic effect of HGF, and allow FSH-dependent $\mathrm{E}_{2}$ production to proceed unimpeded. Since HGF blocked LH-stimulated androgen production in theca cells, yet theca cells of large antral follicles contain c-met and HGF, yet-to-be identified mechanisms must arrest the reported HGFdependent block in androgen synthesis during advanced folliculogenesis. Of interest would be the identification of intrafollicular growth factors and/or further elaboration of the intraovarian HGFA and HAI mechanisms which could block the suppressive effect of HGF on theca cell androgen production.

Since an expanding body of experimental evidence indicates that HGF is a key regulatory factor of ovarian function, it is plausible that a loss of intraovarian HGF responsiveness would severely disrupt follicle development and thereby induce female reproductive failure. When all of these data are considered, one glaring question remains: is an intraovarian HGF system required for normal ovarian function to occur in vivo? This question cannot be definitively answered using in vitro methods; however, knockout transgenics provide a promising technology to address this issue. Importantly, homozygous null mutant mice, which lack either the endogenous production of HGF or c-met, die during gestation due to placental and developmental defects (Uehara et al. 1995). Thus, in order to define the intraovarian function of HGF in vivo, a cell-specific, conditional knockout approach is a plausible and attractive method which could address these questions.

\section{The testis}

Many parallel mechanisms exist when comparing ovarian and testicular function. Like the ovary, the testis comprises distinct cell populations which work in concert to control fertility. Testicular cells include germ cells, as well as Leydig and Sertoli

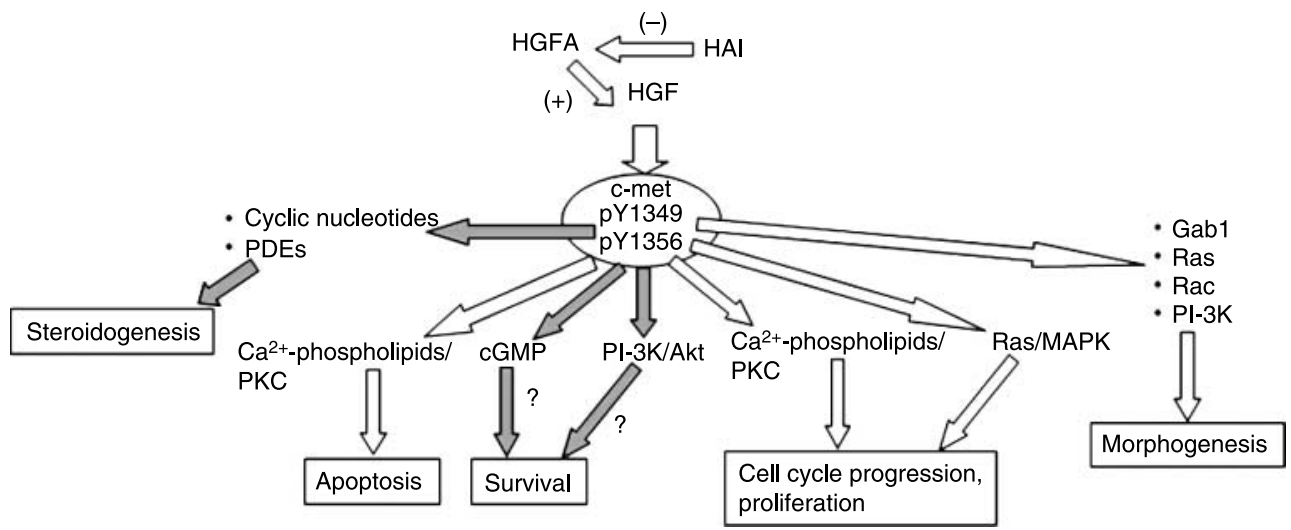

Figure 2 A summary of HGF-dependent signal transduction. Shown are some of the signaling cascades known to be activated by HGF. The co-localization of HGFA (as detected in growing rat follicles) and HAI proteins in tissues concomitantly expressing HGF and c-met suggests a mechanism for the local modulation of HGF bioactivity. The initial steps of HGF-directed signal transduction involve HGF binding to c-met and the subsequent autophosphorylation of residues Y1349 and Y1356 within the c-met carboxyl region. Shaded arrows show cascades affected by HGF within GC. HGF modulates cAMP and cGMP content and cyclic nucleotide phosphodiesterase (PDE) activity in GC. These effects occur during the time course for HGF-induced suppression of FSH- and FSH + IGF-I-stimulated $\mathrm{E}_{2}$ synthesis. Also, HGF increases the steady-state level of Akt1 mRNA in GC; this effect, taken together with increased cGMP content, may mediate the observed anti-apoptotic effect of HGF in GC, although this link has not been confirmed. In non-ovarian cells, HGF mobilizes many signaling molecules including the Ras-MAPK and $\mathrm{Ca}^{2+}$-phospholipid-dependent signaling cascades which have been linked with HGF-orchestrated changes in apoptosis, cell cycle progression, and proliferation. The recruitment of adaptor proteins (Gab1, Ras, Rac, and PI-3K) to the multifunction docking site within the c-met PTK domain has been coupled to HGF-dependent morphogenesis. 


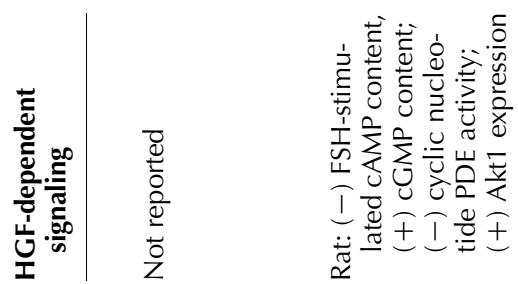

$\frac{\sqrt{\pi}}{+\frac{1}{\pi}}$

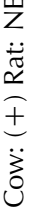
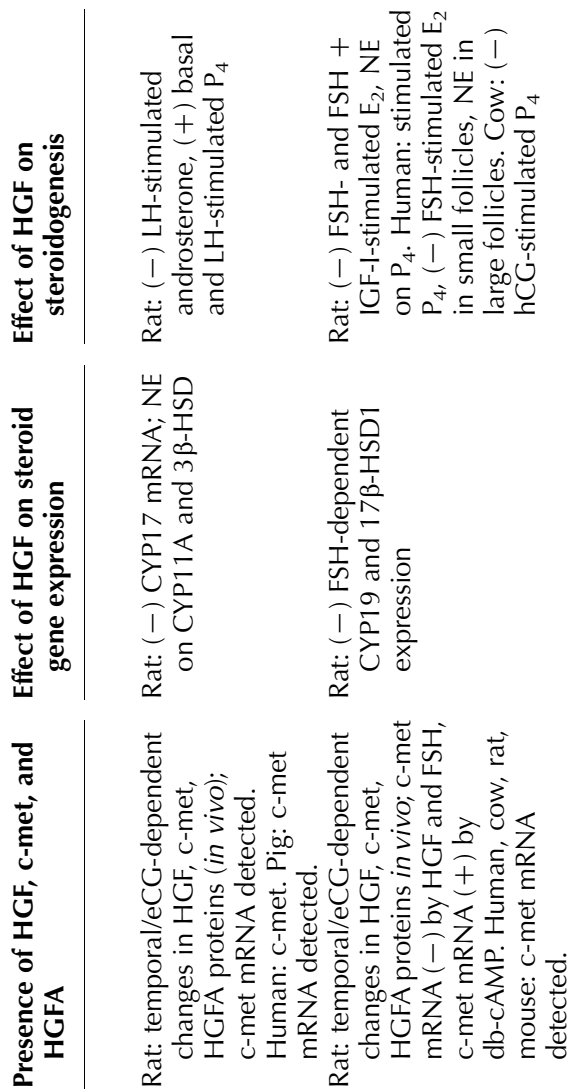

$\frac{\pi}{\frac{0}{3}}$ cells. Leydig and Sertoli cells respond to $\mathrm{LH}$ and FSH respectively, to produce androgens (testosterone), $\mathrm{E}_{2}$, several growth factors, and cytokines which control testicular differentiation and function (Bornstein et al. 2004, Haider 2004, Rao 2005, Itman et al. 2006, Mackay \& Smith 2007).

The precise function of testicular $\mathrm{E}_{2}$ remains debatable, and has been thoroughly reviewed elsewhere (Sierens et al. 2005, Carreau et al. 2006). However, through the collective production of testosterone, several growth factors (including HGF), and other proteins, Leydig and Sertoli cells (like ovarian theca cells and GC) cooperate to support germ cell maturation, and are thus vital for male reproductive health.

In addition to Sertoli and Leydig cells, peritubular myoid cells represent another somatic cell type which is involved in epithelial-mesenchymal interactions within the testis. During embryonic gonadal development, peritubular myoid cells differentiate from cells that migrate from neighboring mesonephros, which is essential for normal testicular cord formation (Tilmann \& Capel 1999). During postnatal life, peritubular myoid cells provide normal tubule morphology and contractility, processes that are critical for spermatogenesis (Zhang et al. 2006). Peritubular myoid cells and Sertoli cells interact with each other through growth factor-mediated feedback; these cells collaborate to produce extracellular matrix components which comprise the basement membrane that separates these two cell types (Skinner et al. 1985, Skinner 1991).

\section{The ontogeny of HGF and c-met expression during testicular development}

As with the ovary, the testis contains an endogenous HGF system, with a pattern of expression for HGF and c-met which is species specific. Although there are no published reports to date showing the ontogeny of HGF and/or c-met expression during ovarian development, changes in HGF and c-met expression during embryonic and postnatal testicular development have been described (Catizone et al. 1999, 2005, Ricci et al. 1999, 2002, 2006).

HGF expression starts in the mesonephros and coelomic epithelium of the undifferentiated male urogenital ridge as early as 11.5 day post-coitum (dpc) in the mouse (Ricci et al. 2002), and remains within the interstitium (presumably in peritubular myoid cells). Although c-met is first expressed inside the cords starting on $12.5 \mathrm{dpc}$, it is not clear at this time whether c-met is expressed by Sertoli or germ cells within cords. However, based on the classical paracrine model proposed for the HGF/c-met system (suggesting that HGF is produced by mesenchymal cells and acts on epithelial cells), Sertoli cells are the likely target for HGF within the cords. Ricci et al. (2006) reported that in the mouse at 13.5 and $15.5 \mathrm{dpc}$, c-met was mainly present within the testicular cords, and by $18.5 \mathrm{dpc}$, c-met was more localized to the interstitium (presumably fetal Leydig cells) and is no longer expressed in the cords (Table 2).

In the rat, however, c-met mRNA and immunoreactive protein were detected in the postnatal testis on day 10, with expression appearing in Sertoli cells on day 25, and increasing 
A

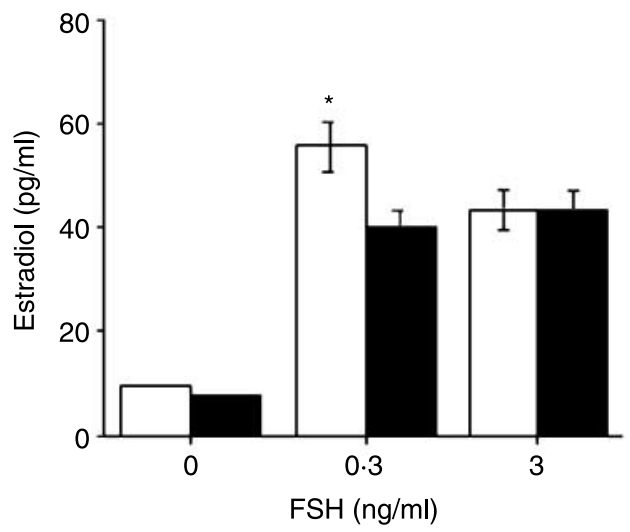

B

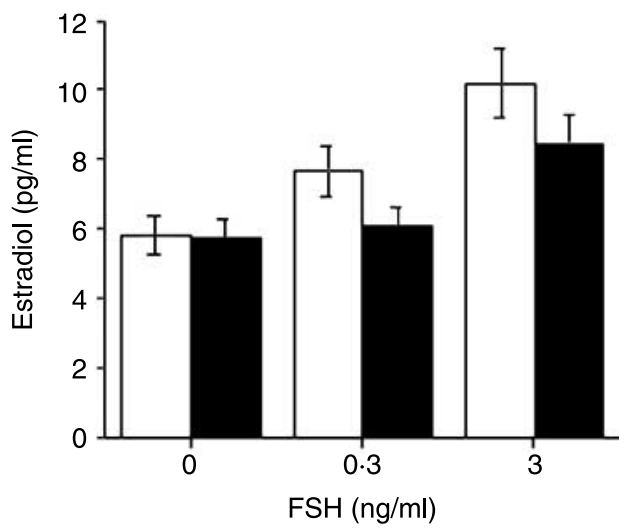

Control

HGF $(30 \mathrm{ng} / \mathrm{ml})$

Figure 3 Effect of HGF on $\mathrm{E}_{2}$ production in GC from small (A) versus large diameter (B) human follicles. Follicles were isolated from normal human ovaries following removal for non-ovarian pathology. GCs were harvested by follicle puncture and incubated for $48 \mathrm{~h}$ in the presence of testosterone with and without FSH+ HGF. Specific RIA was used to measure the level of $E_{2}$ in conditioned media. Values shown are the mean \pm S.E.M. from triplicate treatments from two independent experiments. Significantly different $(P \leq 0 \cdot 05)$ levels of $E_{2}$ (HGF versus control) were determined using one-way ANOVA followed by Tukey's test and are indicated by an asterisk.

at day 35 (Catizone et al. 2001). In another study using $15 \cdot 5$ and $18.5 \mathrm{dpc}$ mice, immunoreactive HGF was detected within the tunica albuginea, interstitium, and peritubular myoid cells, but was not found within Leydig cells (Ricci et al. 2006). In the postnatal rat testis, HGF is produced by myoid cells, and intratesticular HGF was purportedto stimulate c-met expression in Sertoli cells (Catizone et al. 2005).

In contrast to the diverse palate of regulatory functions which have been shown for HGF within ovarian follicle cells, within the testis, HGF bioactivity appears to be relatively more specific to critical morphogenic effects during embryonic and postnatal development (Catizone et al. 2001, 2002, 2005, 2006, Ricci et al. 2006). Noteworthy is the observation that germ cells express c-met in human and rat testes (Depuydt et al. 1996, Catizone et al. 2006). Interestingly, using the adenoviralmediated overexpression and a postnatal testis tissue culture system, HGF was shown to block apoptosis and stimulate proliferation of germ cells in the rat testis (Goda et al. 2004, Catizone et al. 2006). These findings show similarities with the proposed anti-apoptotic function of HGF within ovarian GC described above (Uzumcu et al. 2006). If such an effect occurs under normal conditions in vivo, this would indicate an essential role of the intratesticular HGF system in controlling male fertility by affecting fetal testicular development and adult testicular function.

We propose that another similarity may exist between the roles of the HGF system in the ovary and the testis if it is found that HGF controls prepubertal $\mathrm{E}_{2}$ production in Sertoli cells. To elaborate, HGF and c-met are not expressed in Sertoli cells on postnatal day 10 (Catizone et al. 1999, 2001) when Sertoli cells are capable of producing a greater quantity of $\mathrm{E}_{2}$ (Le Margueresse \& Jegou 1988). Whereas on postnatal day 25, Sertoli cells first show the expression of HGF and c-met (Catizone et al. 2001, 2005); interestingly, this is the time when $E_{2}$ production by Sertoli cells is reduced (Le Margueresse \& Jegou 1988). Since the HGF-dependent suppression of $\mathrm{E}_{2}$ was observed in rodent and human GC, it is plausible that HGF may control this aspect of the Sertoli differentiation; a novel mechanism which is worth further investigation.

\section{HGF and Sertoli cells}

In response to FSH, testosterone, and growth factors, Sertoli cells maintain a microenvironment that is conducive for spermatogenesis (Griswold 1998, Huleihel \& Lunenfeld 2004, Walker \& Cheng 2005). During embryonic life, sex-determining region of Y chromosome (Sry) expression initiates Sertoli cell differentiation leading to testis development (Sinclair et al. 1990). Paracrine growth factors expressed in the differentiating testis mediate the action of Sry. For example, FGF-9 exerts a significant role in critical cellular events during testis differentiation, such as mesonephric cell migration, Sertoli cell proliferation, and ultimately cord formation (Schmahl et al. 2004). In the absence of FGF-9, testicular abnormalities ranging from testicular hypoplasia to sex reversal occur in XY (i.e., genetically male) embryos (Colvin et al. 2001). Platelet-derived growth factors (PDGFs; Colvin et al. 2001, Uzumcu et al. 2002b, Brennan et al. 2003) constitute another group of paracrine growth factors which function in Leydig cell differentiation as well as other cellular events downstream from Sry activation (Brennan et al. 2003). 
Table 2 Ontogeny and functions of c-met and hepatocyte growth factor (HGF) in the prenatal (mouse) and postnatal (rat) testis

\section{Fetal $(\mathrm{dpc})$}

$12 \cdot 5$

$$
13 \cdot 5
$$$$
15 \cdot 5
$$

Cells

Sertoli

c-met, (C) (Ricci c-m et al. 1999)

et al. 1999)
et

10

t-natal $(d)$

20

30-35

60

-) (Catizone

-) (Catizone

$(-)$ (Catizone
et al. 1999, 2001)

c-m

c-met, (C) (Ricci c-met, (C) (Ricci c-met, (C) (Ricci (-) (Ricci et al. et al. 1999) et al. 2006) 2006)

c-met (Catizone c-met (Catizone et al. 2006) et al. 2004 (-) (Ricci et al. (-) (Ricci et al. (-) (Ricci et al. (-) (Ricci et al. 1999) HGF, (I) 2006) HGF, (I) 2006) HGF, (I)

(Ricci et al.

(Ricci et al.

(Ricci et al.

et al. 2001)

-met (Catizon

HGF et al. 1999)

(Catizone et (Catizone et

al. 2005) al. 1999

c-met, (I) (Cati- c-met, (I) (Cati-

$\begin{array}{lcc}\begin{array}{lc}\text { c-met (Catizone } \\ \text { et al. 2001) }\end{array} & \text { c-met (Catizone } \\ \text { HGF (Cati- } & \text { HGF (Cati- } & \\ \text { zone et al. } & \text { zone et al. } & \\ \text { 2005) } & \text { 2005) } & \\ & \text { C-met (Catizone } & \text { c-met (Catizone } \\ \text { et al. 2006) } & \text { et al. 2002) } \\ & \text { c-met (Catizone } & \\ & \text { et al. 2001) } \\ & \text { HGF (Cati- } \\ & \text { zone et al. } \\ & \text { 2005) } \\ & \text { C-met (Catizone } \\ & \text { et al. 2001) }\end{array}$

Shown or

zone et al. zone et al. 1999)

Germ cell survival, proliferation, and motility (Catizone et al. 2002, 2006, Naz et al. 1994)

Cord formation and development (Ricci et al. 1999) $\begin{array}{r}\text { Fetal Leydig cell } \\ \text { steroidogenesis }\end{array}$

(Ricci

et al. 2006)

Seminiferous tubule formation \& Sertoli cell differentiation (Catizone et al. 2001, 2005, van der Wee \& Hofmann 1999)

Leydig cell survival and steroidogenesis (Del Bravo et al. 2007) 
The inhibition of PDGF bioactivity or deletion of PDGFR- $\alpha$ causes abnormal cord formation (Uzumcu et al. 2002b, Brennan et al. 2003).

Additional paracrine factors with important functions in the developing testis are neurotrophins (Cupp et al. 2000, Levine et al. 2000), TGF- $\beta$ (Cupp et al. 1999), VEGF (Bott et al. 2006), kit ligand (Vincent et al. 1998), and glial cell line-derived neurotropic factor (GDNF; Meng et al. 2000). The roles of these growth factors in promoting testicular differentiation and development have been extensively reviewed elsewhere (Brennan \& Capel 2004, Mackay \& Smith 2007).

HGF is somewhat unique among growth factors. Unlike the growth factors mentioned above that are mainly products of Sertoli cells (an epithelial cell type) and act on mesenchymal cells, HGF is primarily produced by myoid cells (a mesenchymal cell type), especially during embryonic development. Thus, when considering communication between Sertoli and myoid cells, HGF represents an interesting growth factor because it mostly acts in the mesenchymal-to-epithelial direction. The identification of c-met within Sertoli cells enforces the validity of this model.

The pattern of c-met expression within the cords during embryonic life is not exactly known, but beginning sometime between postnatal days 20-25 (in the rat), Sertoli cells contain functional c-met protein (Catizone et al. 2001). In dissociated rat Sertoli cells in vitro, the administration of exogenous HGF induces the formation of structures resembling testicular seminiferous cords (Catizone et al. 2001). This experimental observation led to the notion that HGF may be instrumental in testicular lumen formation in mature animals (Catizone et al. 2001). It is also imperative to consider that testicular cord formation is a major morphologic event during embryonic gonad development in the male (Uzumcu et al. 2002a,b). This process requires Sertoli cell growth and differentiation, as well as mesonephric cell migration (reviewed in (Yao et al. 2002), changes which may be mediated by HGF (Ricci et al. 1999). Overall, the available evidence then suggests that HGF is one of several growth factors (including TGF- $\beta$, FGF-9, PDGF, neurotrophins, GDNF, VEGF, and others) with an important role in development and function of the testis including cord formation and Sertoli cell differentiation.

\section{HGF and myoid cells}

It seems that HGF has two different modes of action depending upon the stage of development. Initially, during the embryonic developmental stage, the mode of action used by HGF is essentially paracrine. Thus, HGF from myoid cells targets cells inside the seminiferous cords (i.e., Sertoli cells and/or germ cells) between $12 \cdot 5$ and $15 \cdot 5 \mathrm{dpc}$, and then acts on fetal Leydig cells on 18.5 dpc (Ricci et al. 1999, 2002, 2006). However, a switch occurs during postnatal developmental, when HGF activity becomes primarily autocrine, with some paracrine function still operational.

Both HGF and c-met are expressed in myoid cells prior to postnatal day 25. After day 25, the expression of HGF and c-met appears in Sertoli cells, while the expression of HGF and c-met in myoid cells is relatively subsided (Catizone et al. 1999, 2001, 2006). In addition to myoid and Sertoli cells, c-met mRNA is also present in germ cells between postnatal days 10 and 60 (Catizone et al. 2002, 2006), and in Leydig cells in adolescent rats (days 30-32; Del Bravo et al. 2007).

\section{HGF and Leydig cells}

The testicular correlate of the ovarian theca cell is the Leydig cell. As such, Leydig cells do not express FSH receptors, but do express LH receptors, and are stimulated by LH to produce testosterone as the predominant steroid. Beginning around fetal day 18.5 , c-met is expressed within the mouse testicular interstitium; and organ culture of fetal day 18.5 testes revealed that HGF stimulated basal testosterone secretion (Ricci et al. 2006). Postnatal (days 30-32) rat Leydig cells also express immunoreactive c-met, and HGF stimulates basal testosterone secretion and inhibits apoptosis in rat Leydig cells as well as testicular tissue explants (Del Bravo et al. 2007).

\section{Proposed regulatory function for HGF in the testis}

What is apparent is that shifts in the expression of c-met and HGF between Sertoli cells, germ cells, Leydig cells, and myoid cells during fetal and postnatal testicular growth and differentiation suggest that HGF guides changes in testicular morphogenesis and function (including steroidogenesis) in a developmentally regulated manner. This type of model overlaps with that proposed for HGF during folliculogenesis. One hypothesis which can be derived from these data from the testis is that HGF promotes Sertoli cell differentiation and cord formation during in utero development, but then HGF control switches to the regulation of Leydig cell steroidogenic differentiation during the last stages of fetal development and preceding sexual maturity. Beginning around the time of puberty (i.e., day 25 in the rodent), Sertoli cells resume the expression of c-met (Table 2), and once again gain HGF responsiveness. It is possible that, in the prepubertal male, HGF controls Sertoli cell function at multiple levels, to potentially include the modulation of $\mathrm{FSH}$-stimulated $\mathrm{E}_{2}$ production and cell growth; this, however, remains uncertain pending future studies. By regulating Sertoli cell function, HGF would indirectly control sperm growth and maturation, in addition to the direct effects of HGF on sperm function.

The stimulatory effect of HGF on steroid production in postnatal Leydig cells has recently been reported (Del Bravo et al. 2007). Based upon the most current data, HGF directly stimulates rat Leydig cell steroidogenesis, although mature human Leydig cells do not express c-met (Depuydt et al. 1996, Catizone et al. 2001). Considering that any effects of HGF are plausibly species specific, as has been documented with the ovarian HGF system, this difference is not surprising. What has been substantiated is that, collectively, the intratesticular HGF system has several potentially vital roles, those being the regulation of 1) seminiferous cord formation and development, 
2) Leydig cell steroidogenesis and survival, 3) Sertoli cell proliferation and terminal differentiation, and 4) germ cell function and/or survival. To date, the ability of HGF to control testicular function in vivo (i.e., male reproductive viability) has not been reported. Considering that the either HGF or c-met null mutations are embryonic lethal (as described above), a tissue-specific conditional knockout approach is needed to establish the importance of the HGF system in regulating testis development and function in vivo.

\section{Concluding thoughts}

Data from several laboratories have shown that HGF controls many key functions within the ovary and testis; these range from modulation of both steroidogenesis (Parrott et al. 1994, Zachow et al. 1997, 2000, Ito et al. 2001, Ricci et al. 2006, Del Bravo et al. 2007) and apoptosis (Goda et al. 2004, Uzumcu et al. 2006, Del Bravo et al. 2007), to guiding mitosis and morphogenesis (Parrott \& Skinner 1998b, Catizone et al. 2001, 2006, Ricci et al. 2002, 1999). The breadth of the HGF-mediated control mechanisms strongly indicates that an intact HGF system is required for proper gonad development and/or function; this would of course make HGF a key regulator of female and male fertility. The next step in determining this is to blend in vitro, molecular mechanism studies with an elucidation of the role of HGF in regulating reproductive function in vivo.

\section{Acknowledgements}

The authors declare that there is no conflict of interest that would prejudice the impartiality of this scientific work.

\section{References}

Baffy G, Yang L, Michalopoulos GK \& Williamson JR 1992 Hepatocyte growth factor induces calcium mobilization and inositol phosphate production in rat hepatocytes. Journal of Cell Physiology 153 332-339.

Barnett KR, Schilling C, Greenfeld CR, Tomic D \& Flaws JA 2006 Ovarian follicle development and transgenic mouse models. Human Reproduction Update 12 537-555.

Bornstein SR, Rutowski H \& Vrezas I 2004 Cytokines and steroidogenesis. Molecular and Cellular Endocrinology 215 135-141.

Bott RC, McFee RM, Clopton DT, Toombs C \& Cupp AS 2006 Vascular endothelial growth factor and kinase domain region receptor are involved in both seminiferous cord formation and vascular development during testis morphogenesis in the rat. Biology of Reproduction 75 56-67.

Bottaro DP, Rubin JS \& Faletto DL 1991 Identification of the hepatocyte growth factor receptor as the c-met proto-oncogene product. Science $\mathbf{2 5 1}$ 802-804.

Brennan J \& Capel B 2004 One tissue, two fates: molecular genetic events that underlie testis versus ovary development. Nature Review Genetics 5 509-521.

Brennan J, Tilmann C \& Capel B 2003 Pdgfr-alpha mediates testis cord organization and fetal Leydig cell development in the XY gonad. Genes and Development 17 800-810.

Burns KH \& Matzuk MM 2002 Genetic models for the study of gonadotropin actions. Endocrinology 143 2823-2835.
Bussolino F, DiRenzo M, Ziche M, Bocchietto E, Olivero M, Naldini L, Gaudino G, Tomagnone L, Coffer A \& Comoglio P 1992 Hepatocyte growth factor is a potent angiogenic factor which stimulates endothelial cell motility and growth. Journal of Cell Biology 119 629-641.

Carreau S, Dalande C, Silandre D, Bourguiba S \& Lambard S 2006 Aromatase and estrogen receptors in male reproduction. Molecular and Cellular Endocrinology 246 65-68.

Catizone A, Ricci G, Arista V, Innocenzi A \& Galdieri M 1999 Hepatocyte growth factor and c-Met are expressed in the rat prepubertal testis. Endocrinology 140 3106-3113.

Catizone A, Ricci G \& Galdieri M 2001 Expression and a functional role of hepatocyte growth factor receptor (c-Met) during postnatal rat testis development. Endocrinology 142 1828-1834.

Catizone A, Ricci G \& Galdieri M 2002 Functional role of hepatocyte growth factor receptor during sperm maturation. Journal of Andrology 23 911-918.

Catizone A, Ricci G \& Galdieri M 2005 HGF and post-natal testis development. Molecular and Cellular Endocrinology 241 32-40.

Catizone A, Ricci G, Del Bravo J \& Galdieri M 2006 Hepatocyte growth factor modulates in vitro cell survival and proliferation of germ cells during postnatal testis development. Journal of Endocrinology 189 137-146.

Colvin JS, Green RP, Schmal J, Capel B \& Ornitz DM 2001 Male-to-female sex reversal in mice lacking fibroblast growth factor 9. Cell 104 875-889.

Conti M, Hsieh M, Park YJ \& Su YQ 2006 Role of the epidermal growth factor network in ovarian follicles. Molecular Endocrinolgy 20 715-723.

Cupp AS, Kim G \& Skinner MK 1999 Expression and action of transforming growth factor $\beta$ (TGF $\beta 1$, TGF $\beta 2$ and TGF $\beta 3$ ) during embryonic rat testis development. Biology of Reproduction 60 1304-1313.

Cupp AS, Kim GH \& Skinner MK 2000 Expression and action of neurotropin-3 and nerve growth factor in embryonic and early postnatal rat testis development. Biology of Reproduction 63 1617-1628.

Del Bravo J, Catizone A, Ricci G \& Galdieri M 2007 Hepatocyte growth factor modulates rat Leydig cell functions. Journal of Andrology In Press.

Depuydt CE, Zalata A, de Potter CR, van Emmelo J \& Comhaire FH 1996 The receptor encoded by human c-met oncogene is expressed in testicular tissue and on human spermatozoa. Molecular Human Reproduction 2 2-8.

Ehrmann DA 2005 Polycystic ovary syndrome. New England Journal of Medicine $3251223-1236$

Erickson GF 1983 Primary cultures of ovarian cells in serum-free medium as models of hormone-dependent differentiation. Molecular and Cellular Endocrinology 29 21-49.

Erickson GF 1994 Polycystic ovary syndrome: normal and abnormal steroidogenesis. In Ovarian Endocrinopathies: Proceedings of the 8th Reinier de Graaf Symposium, pp 103-115. Eds R Schats \& J Schoemaker. New York: Parthenon Publishing.

Fortune JE 2003 The early stages of follicular development: activation of primordial follicles and growth of preantral follicles. Animal Reproduction Science 78 135-163.

Gheradi E \& Stoker M 1991 Hepatocyte growth factor-scatter factor: mitogen, motogen, and Met. Cancer Cell 3 227-232.

Giordano S, Ponzetto C \& DiRenzo MF 1989 Tyrosine kinase receptor indistinguishable from the c-met protein. Nature 339 155-156.

Goda K, Fujisawa M, Shirakawa T, Dobashi M, Shiota G, Zhang ZJ, Gotoh A \& Kamidono S 2004 Adenoviral-mediated HGF expression inhibits germ cell apoptosis in rats with cryptorchidism. Journal of Gene Medicine 6 869-876.

Gonzatti-Haces M, Seth A, Park M, Copeland T, Oroszlan S \& Vande Woude GF 1988 Characterization of the tpr-met oncogene p65 and the met protooncogene $\mathrm{p} 140$ protein tyrosine kinases. PNAS 85 21-25.

Griswold MD 1998 The central role of Sertoli cells in spermatogenesis. Seminars in Cell and Developmental Biology 9 411-416.

Haider SG 2004 Cell biology of Leydig cells in the testis. International Review of Cytology 233 181-241.

Hillier SG 2001 Gonadotropic control of ovarian follicular growth and development. Molecular and Cellular Endocrinology 179 39-46.

Hsueh AJ, Eisenhauer K, Chun SY, Hsu SY \& Billig H 1996 Gonadal cell apoptosis. Recent Progress in Hormone Research 51 433-455.

Huleihel M \& Lunenfeld E 2004 Regulation of spermatogenesis by paracrine/autocrine testicular factors. Asian Journal of Andrology 6 259-268. 
Hussein MR 2005 Apoptosis in the ovary: molecular mechanisms. Human Reproduction Update 11 162-177.

Itman C, Mendis S, Barakat B \& Loveland KL 2006 All in the family: TGF-beta family action in testis development. Reproduction 132 233-246.

Ito M, Harada T, Tanikawa M, Fuji A, Shiota G \& Terakawa N 2001 Hepatocyte growth factor and stem cell factor involvement in paracrine interplays of theca and granulosa cells in the human ovary. Fertility and Sterility 75 973-979.

Kaipia A \& Hsueh AJ 1997 Regulation of ovarian follicle atresia. Annual Review of Physiology 59 349-363.

Knight PG \& Glister C 2006 TGF-beta superfamily members and ovarian follicle development. Reproduction 132 177-178.

Lail-Trecker M, Gulati R \& Peluso JJ 1998 A role for hepatocyte growth factor/scatter factor in regulating normal and neoplastic cells of reproductive tissues. Journal of the Society for Gynecologic Investigations 5 114-121.

LaPolt PS \& Hong LS 1995 Inhibitory effects of superoxide dismutase and cyclic guanosine $3^{\prime}, 5^{\prime}$-monophosphate on estrogen production in cultured rat granulosa cells. Endocrinology $1365533-5539$.

Levine E, Cupp AS \& Skinner MK 2000 Role of neurotropins in rat embryonic testis morphogenesis (cord formation). Biology of Reproduction 62 132-142.

Liu Y 1999 Hepatocyte growth factor promotes renal epithelial cell survival by dual mechanisms. American Journal of Physiology 277 F624-F633.

Liu Y, Lin L \& Zarnegar R 1994 Modulation of hepatocyte growth factor gene expression by estrogen in mouse ovary. Molecular and Cellular Endocrinology 104 173-181.

Mackay S \& Smith RA 2007 Effects of growth factors on testicular morphogenesis. International Review of Cytology 260 113-173.

Magoffin DA 1991 Regulation of differentiated functions in ovarian theca cells. Seminars in Reproductive Endocrinology 9 321-331.

Makondo K, Kimura K, Kitamura N, Kitamura T, Yamaji D, Jung BD \& Saito M 2004 Hepatocyte growth factor activates endothelial nitric oxide synthase by $\mathrm{Ca}(2+)$ - and phosphoinositide 3-kinase/Akt-dependent phosphorylation in aortic endothelial cells. Biochemistry Journal 374 63-69.

Le Margueresse B \& Jegou B 1988 In vitro effects of germ cells on the secretory activity of Sertoli cells recovered from rats of different ages. Endocrinology 122 1672-1680.

Matzuk MM, Burns KH, Viveiros MM \& Eppig JJ 2002 Intercellular communication in the mammalian ovary: oocytes carry the conversation. Science 296 2178-2180.

Maulik G, Shrikhande A, Kijima T, Ma PC, Morrison PT \& Salgia R 2002 Role of hepatocyte growth factor receptor, c-Met, in oncogenesis and potential for therapeutic inhibition. Cytokine and Growth Factor Reviews 13 41-59.

McNatty KP, Juengel JL, Reader KL, Lun S, Myllymaa S, Lawrence SB, Western A, Meerasahib MF, Mottershead DG, Groome NP et al. 2005 Bone morphogenetic protein 15 and growth differentiation factor 9 cooperate to regulate granulosa cell function in ruminants. Reproduction 129 481-487.

Meng X, Lindahl M, Hyvonen ME, Parvinen M, de Rooij DG, Hess MW, Raatikainen-Ahokas A, Sainio K, Rauvala H, Lakso M et al. 2000 Regulation of cell fate decision of undifferentiated spermatogonia by GDNF. Science 287 1489-1493.

Miyazawa K, Tsubouchi H, Naka D, Takahashi K, Okigaki M, Arakaki N, Nakayama H, Hirono S, Sakiyama O, Takahashi K et al. 1989 Molecular cloning and sequence analysis of cDNA for human hepatocyte growth factor. Biochemical and Biophysical Research Communications 163 967-973.

Miyazawa K, Shimomura T, Kitamura A, Kondo J, Morimoto Y \& Kitamura N 1993 Molecular cloning and sequence analysis of the cDNA for a human serine protease responsible for activation of hepatocyte growth factor, structural similarity of the protease precursor to blood coagulation factor-xii. Journal of Biological Chemistry 269 10024-10028.

Nakamura T, Nishizawa T, Hagiya M, Seki T, Shimonishi M, Sugimura A, Tashiro K \& Shimizu S 1989 Molecular cloning and expression of human hepatocyte growth factor. Nature 342 440-443.

Naz RK, Joseph A, Lee Y, Ahmad K \& Bhargava MM 1994 Expression of scatter factor/hepatocyte growth factor is regionally correlated with the initiation of sperm motility in murine male genital tract: is scatter factor/hepatocyte growth factor involved in the initiation of sperm motility. Molecular Reproduction and Development 38 431-439.

Osuga Y, Tsutsumi O, Momoeda M, Okagaki R, Matsumi H, Hiroi H, Suenaga A, Yano T \& Taketani Y 1999 Evidence for the presence of hepatocyte growth factor expression in human ovarian follicles. Molecular Human Reproduction 5 703-707.

Parrott JA \& Skinner MK 1998a Developmental and hormonal regulation of hepatocyte growth factor expression and action in the bovine ovarian follicle. Biology of Reproduction 59 553-560.

Parrott JA \& Skinner MK 19986 Theca cell-granulosa cell interactions involve a positive feedback loop among keratinocyte growth factor, hepatocyte growth factor, and kit ligand during ovarian follicular development. Endocrinology 139 2240-2245.

Parrott JA \& Skinner MK 2000 Kit ligand actions on ovarian stromal cells: effects on theca cell recruitment and steroid production. Molecular Reproduction and Development 55 55-64.

Parrott JA, Vigne JL, Chu BZ \& Skinner MK 1994 Mesenchymal epithelial interactions within the ovarian follicle involve keratinocyte and hepatocyte growth factor production by theca cells and their action on granulosa cells. Endocrinology 135 569-575.

Peluso JJ \& Pappalardo A 2004 Progesterone regulates granulosa cell viability through a protein kinase G-dependent mechanism that may involve 14-3-3-s. Biology of Reproduction 71 1870-1878.

Peruzzi B \& Bottaro DP 2006 Targeting the c-Met signaling pathway in cancer. Clinical Cancer Research 12 3657-3660.

Rao AJ 2005 Hormonal regulation of Leydig cell proliferation and differentiation in rodent testis: a dynamic interplay between gonadotropins and testicular factors. Reproductive Biomedicine Online 11 507-518.

Ricci G, Catizone A, Innocenzi A \& Galdieri M 1999 Hepatocyte growth factor (HGF) receptor expression and role of HGF during embryonic mouse testis development. Developmental Biology 216 340-347.

Ricci G, Catizone A \& Galdieri M 2002 Pleiotropic activity of hepatocyte growth factor during embryonic mouse testis development. Mechanism of Development 118 19-28.

Ricci G, Catizone A \& Galdieri M 2006 Expression and functional role of hepatocyte growth factor and its receptor (c-met) during fetal mouse tesis development. Journal of Endocrinology 191 559-570.

Roy A \& Matzuk MM 2006 Deconstructing mammalian reproduction: using knockouts to define fertility pathways. Reproduction 131 207-219.

Schmahl J, Kim Y, Colvin JS, Ornitz DM \& Capel B 2004 Fgf-9 induces proliferation and nuclear localization of FGFR2 in Sertoli precursors during male sex determination. Development 131 3627-3636.

Shimizu T, Ijima K, Sasada H \& Sato E 2003 Messenger ribonucleic acid expressions of hepatocyte growth factor, angiopoietins and their receptors during follicular development in gilts. Journal of Reproduction and Development 49 203-211.

Shimomura T, Denda K, Kitamura A, Kawaguchi T, Kito M, Kondo J, Kagaya S, Qin L, Takata H, Miyazawa K et al. 1997 Hepatocyte growth factor activator inhibitor, a novel Kunitz-type serine protease inhibitor. Journal of Biological Chemistry 272 6370-6376.

Sierens JE, Sneddon SF, Collins F, Millar MR \& Saunders PTK 2005 Estrogens in testis biology. Annals of New York Academy of Sciences 1061 65-76.

Sinclair AH, Berta P, Palmer MS, Hawkins JR, Griffiths BL, Smith MJ, FosterJW, Frischauf AM, Lovell-Badge R \& Goodfellow PN 1990 A gene from the human sex-determining region encodes a protein with homology to a conserved DNA-binding motif. Nature 346 240-244.

Skinner MK 1991 Cell-cell interactions in the testis. Endocrine Reviews 12 $45-77$.

Skinner MK 2005 Regulation of primordial follicle assembly and development. Human Reproduction Update 11 461-471.

Skinner MK, Tung PS \& Fritz IB 1985 Cooperativity between Sertoli cells and testicular peritubular cells in the production and deposition of extracellular matrix components. Journal of Cell Biology 100 1941-1947.

Terranova PF 1991 Regulation of the granulosa cell: growth factor interactions. Seminars in Reproductive Endocrinology 9 313-320. 
Tilmann C \& Capel B 1999 Mesonephric cell migration induces testis cord formation and Sertoli cell differentiation in the mammalian gonad. Development 126 2883-2890.

Uehara Y, Minowa O, Mori C, Shiota K, Kuno J, Noda T \& Kitamura N 1995 Placental defect and embryonic lethality in mice lacking hepatocyte growth factor/scatter factor. Nature 373 702-705.

Uzumcu M, Dirks KA \& Skinner MK 2002a Inhibition of platelet-derived growth factor actions in the embryonic testis influences normal cord development and morphology. Biology of Reproduction 66 745-753.

Uzumcu M, Westfall SD, Dirks KA \& Skinner MK $2002 b$ Embryonic testis cord formation and mesonephric cell migration requires the phosphotidylinositol 3-kinase signaling pathway. Biology of Reproduction 67 1927-1935.

Uzumcu M, Pan Z, Chu Y, Kuhn PE \& Zachow RJ 2006 Immunolocalization of the hepatocyte growth factor (HGF) system in the rat ovary and the antiapoptotic effect of HGF in rat ovarian granulosa cells in vitro. Reproduction 132 291-299.

Vincent S, Segretain D, Nishikawa S, Nishikawa SI, Sage J, Cuzin F \& Rassoulzadegan M 1998 Stage-specific expression of the Kit receptor and its ligand (KL) during male gametogenesis in the mouse: a Kit-KL interaction critical for meiosis. Development 125 4585-4593.

Vitt UA, Hayashi M, Klein C \& Hsueh AJW 2000 Growth differentiation factor-9 stimulates proliferation but suppresses the follicle-stimulating hormone-induced differentiation of cultured granulosa cells from small antral and preovulatory rat follicles. Biology of Reproduction 62 370-377.

Walker WH \& Cheng J 2005 FSH and testosterone signaling in Sertoli cells. Reproduction 130 15-28.

Webb R, Garnsworthy PC, Gong JG \& Armstrong DG 2004 Control of follicular growth: local interactions and nutritional influences. Journal of Animal Science 82 E63-E74.

Van der Wee K \& Hoffman MC 1999 An in vitro tubule assay identifies HGF as a morphogen for the formation of seminiferous tubules in the postnatal mouse testis. Experimental Cell Research 252 175-185.

Westfall SD, Hendry IR, Obholz KL \& Davis JS 2001 Putative role of phosphatidylinositol 3-kinase-Akt signaling pathway in the survival of granulosa cells. Endocrine 12 315-321.
Yamauchi M, Itoh H, Naganuma S, Koono M, Hasui Y, Osada Y \& Kataoka H 2002 Expression of hepatocyte growth factor activator inhibitor type 2 (HAI-2) in human testis: identification of a distinct transcription start site for the HAI-2 gene in the testis. Biological Chemistry 383 1953-1957.

Yang XM \& Park M 1995 Expression of the hepatocyte growth factor/scatter factor receptor tyrosine kinase is localized to epithelia in the adult mouse. Laboratory Investigation 73 483-491.

Yao HH, Tilmann C, Zhao GQ \& Capel B 2002 The battle of the sexes: opposing pathways in sex determination. Novartis Foundation Symposium 187-198.

Zachow RJ \& Woolery JK 2002 The effect of hepatocyte growth factor on cyclic nucleotide-dependent signaling and steroidogenesis in rat granulosa cells in vitro. Biology of Reproduction 67 454-459.

Zachow RJ, Weitsman SR \& Magoffin DA 1997 Hepatocyte growth factor regulates ovarian theca-interstitial cell differentiation and androgen production. Endocrinology 138 691-697.

Zachow RJ, Ramski BE \& Lee H 2000 Modulation of estrogen production and $17 \beta$-hydroxysteroid dehydrogenase-type 1, cytochrome P450 aromatase, c-Met, and protein kinase $\mathrm{B} \alpha$ messenger ribonucleic content in rat ovarian granulosa cells by hepatocyte growth factor and follicle-stimulating hormone. Biology of Reproduction 62 1851-1857.

Zhang C, Yeh S, Chen YT, Wu CC, Chuang KH, Lin HY, Wang RS, Chang YJ, Mendis-Handagama C, Hu L et al. 2006 Oligozoospermia with normal fertility in male mice lacking the androgen receptor in testis peritubular myoid cells. PNAS 103 17718-17723.
Received in final form 11 September 2007
Accepted 13 September 2007
Made available online as an Accepted Preprint 13 September 2007 